\title{
Study on Dynamic of Ultrafiltration Membrane Materials Preparing and Used in Drinking Water Treatment
}

\author{
Aiyin Chen, Qian Fan, and Qing Tian
}

\begin{abstract}
The ultrafiltration membrane technology as a new water treatment technology, can be used in large scale depends largely on the membrane material itself, also depends on the membrane production conditions and process. This paper reviews the development and research trends of preparing ultrafiltration membrane material, and analyzes its application prospect in water treatment of drinking water.
\end{abstract}

Index Terms-Ultrafiltration, membrane, materials

\section{INTRODUCTION}

Our country mostly use surface water as water source, the vast majority of water is still in the "conventional treatment process of coagulation - sedimentation - Filtration disinfection", the technology can effectively remove suspended, colloidal and pathogenic microorganisms, but the removal efficiency of organic matter is not high. Especially in recent years, with the improvement of living standards, people on drinking water quality is also put forward higher requirements, so the standard of drinking water is becoming more and more strict [1]. But at present, China's serious water environmental pollution, especially water pollution makes the conventional water quality not guaranteed, compared with conventional water treatment technology, membrane separation technology has good water quality, stable operation, small occupation area, easy to realize the automatic control, has an extremely wide application prospect in municipal water treatment industry.

This paper briefly introduces the domestic and foreign types and development situation of materials of preparing ultrafiltration membrane, and the trend of development of preparing ultrafiltration membrane materials were prospect analysis.

\section{The DeVelopment History OF PREPARING Ultrafiltration MEMBRANE MATERIALS}

The materials of preparing ultrafiltration membrane can be divided into inorganic ultrafiltration membrane materials and organic materials of preparing ultrafiltration membrane, application of organic materials of preparing ultrafiltration membrane was originally natural membrane material bovine pericardium, in the eighteen sixties, Loeb and Soufirajan on Californian in the United States invented the

Manuscript received February 1, 2013; revised April 9, 2013. This research is financially supported by National "12th Five-Year" Science and Technology Major Special Projects: "Drinking Water Safe and Control" of China (NO. 2011ZX07410-001, "PVC membrane components and equipment of drinking water treatment industrialization").

The authors are with Water Treatment New Technology Industrialization Base Affiliated to Ministry of Housing \& Urban-Rural Development (MOHURD) of China, Tianjin, China (e-mail: watertech@126.com). immersion preparation of asymmetric cellulose acetate reverse osmosis membrane conversion for the immersion phase inversion membrane production technology, represents the membrane separation technology has entered a new era - polymer (polymer) separation membrane era. To twentieth Century sixty or seventy years, Commercialization process of preparing ultrafiltration membrane materials and polymer membrane has got unprecedented development. The membrane material such as bisphenol A type of cellulose derivatives (PSF), polysulfone polyether sulfone (PES), polysulfone amide (PSA), polyvinylidene fluoride (PVDF), and polyacrylonitrile (PAN), have greatly promoted the development of preparing ultrafiltration membrane materials.

Inorganic materials of preparing ultrafiltration membrane began in the 40's of the last century, developed in the seventy or eighty's. The inorganic materials are the ceramic, zeolite and carbon, etc. But in the domestic or global market, the oxide ceramic inorganic ultrafiltration membranes of single elemental are the most. Ceramic membrane commonly used with $\mathrm{Al}_{2} \mathrm{O}_{3}, \mathrm{ZrO}_{2}$ and $\mathrm{TiO}_{2}$.

\section{Research Status of Preparing Ultrafiltration MEMBRANE MATERIALS}

The materials of preparing ultrafiltration membrane with different led directly to the membrane in the application level difference. The materials of preparing ultrafiltration membrane of different types have different properties, such as cellulose acetate materials with rich source, low price, good hydrophilicity, convenient for industrialized and commercial production [2], polysulfone material with $\mathrm{pH}$ good stability, oxidation resistance, high intensity [3], polyvinylidene fluoride with high mechanical strength, good resistance to oxidation [2], etc.

But in the actual application process, membrane separation technology is still faced with such problems. The most prominent problem is the high operation cost and less selective. A very important reason caused the membrane separation process running a high cost is membrane permeate flux decline and shortened life expectancy caused by membrane fouling $[4,5]$.

Because of the difficulty of single membrane material has good hydrophilicity, chemical stability, membrane-forming property, thermal stability, acid and alkali resistance, microbial corrosion, oxidation resistance and good mechanical strength and so on, hydrophilic modification are processed so far on various ultrafiltration membranes materials such as PVDF, PVC, PSF, PES, PP and PC hydrophobic polymer membrane, to enhance its ability in the permeate flux, resisting pollution, and prolong the service life. Or they are functional modification, give them 
the separation function more and more special properties (such as the choice of coupling, a specific metal ion selective recognition and adsorption, on specific organic molecular self repair, temperature response, $\mathrm{pH}$ response, ionic strength response, light response, biocompatibility and catalysis etc.) to increase the scope of their application and strengthen the application of treatment effect, caused by shortening the improvement of membrane permeate flux decline and membrane life, has become the the focus in the field of membrane science and technology research of membrane material. How to deal with membrane permeate flux decline and membrane life shortening caused by membrane fouling, which has become a hot topic in the current research of science and technology of ultrafiltration membrane materials.

At present China's domestic ultrafiltration membrane modified generally have two kinds of methods: one is modified after ultrafiltration membrane forming process, namely, surface modification. The surface modification methods include plasma modification, surfactant modification, surface coating modification, UV irradiation, surface chemical reaction method, etc. Two is matrix modification before membrane forming process, here mainly refers to the blending modification.

\section{A. Blending Modification}

Blending modification [6[ refers to the method of the process of manufacturing and processing of several materials are evenly mixed, learning performance, comprehensive balance of each polymer component, eliminate the single polymer component performance weakness, obtaining polymer material with perfect comprehensive performance. Blending can effectively improve the performance of polymer processing, membrane materials choice range also can effectively expand, improve the hydrophilicity of the membrane and polymer, and improve the anti-fouling ability of the membrane, then improving the membrane's corrosion resistance, heat resistance and mechanical strength. Blending modification is the use of a wider in the preparation of high performance ultrafiltration membrane.

HMA (wholly aromatic polyamide) and hydrophilic polymer PVP (polyvinylpyrrolidone) are blended by Cherdon, anti-pollution ability and the hydrophilicity of the membrane are stronger than the single membrane materials [7].

PS and acetic acid content of 55\% CA are mixed by Hirogshi, then the ethanol solution of PS /CA alloy membrane in $\mathrm{NaOH}$ obtained by hydrolysis, in order to improve the alloy membrane hydrophilicity and anti-fouling ability. Results show that with the increase of CA saponification degree, the hydrophilicity of the membrane enhanced anti-pollution capacity [8].

By reasonable selection of polymer blends, blend membrane has the characteristics of each polymer preparation, which is an effective method for preparation of membrane materials and expand the range of membrane materials. As reported in the literature at present, study of substances such as polysulfone (PS), PAN, PMMA and sulfonated poly aryl ether sulfone and so on miscible with PVDF to form membrane shows [9-11]: blend membranes after heat treatment, the content of hydrophilic polymer on the surface of the membrane is far higher than the content in the body, improve the anti-fouling ability of the membrane.

At the same time, because of the inorganic ultrafiltration membrane material has its unique advantages (high temperature, acid and alkali resistant), therefore in the research process of ultrafiltration membrane materials, it was found that the organic membrane and inorganic membrane material effectively unifies in together, can get a new organic / inorganic composite materials. The advantages of this material can also be organic membrane and inorganic membrane materials, is one of the hot research at present composite ultrafiltration membrane.

\section{B. Plasma Modification}

Plasma modification is refers to the use of various active particles of the plasma concentration, such as surface ion, electron, free radicals, excited atoms or molecular for bombardment of polymer materials surface, reactive free radicals formed on the surface of polymer materials, initiation of functional monomer by active free radicals and let it on the surface of polymerization or grafted to the surface.

Ulbricht et al. modified on the PAN and PS ultrafiltration membrane by plasma. On the ultrafiltration membrane surface by plasma induced grafting of acrylic acid or methacrylic acid as monomer. The membrane flux was significantly increased, and in maintaining the original protein retention rate at the same time, protein adsorption on the membrane surface pollution markedly improved [12].

\section{Surfactant Method}

Surface active agent method refers to the use of the surfactant polar or hydrophilic functional groups of different media form the directional selectivity of adsorption in solution and membrane interface, changing the quality or state of interface, so as to achieve the purpose of modified.

$\mathrm{Lu}$ Xiaofeng's study shows that, modification of ultrafiltration membrane with surface active agent, enhanced hydrophilicity and increased the membrane flux. But also found that as the filtration time, surfactant gradually in the ultrafiltration membrane would shed, the membrane flux would decline, and would present instability [13].

Surface active agent method is simple, during the increase of functional components in the membrane surface coverage degree, modified effect is more obvious. But due to adsorption on force is weaker van der Waals force, electrostatic force and hydrogen bond force, therefore the modified ultrafiltration membrane performance is not stable enough, this is also the surfactant method faced problems in the application.

\section{Application of Ultrafiltration Membrane Technology in Drinking Water Treatment}

Compared with the traditional water treatment technology, membrane treatment process has the advantages of simple and compact structure, small occupation area, water quality and stability, but also has its limitations, such as easy scaling, regular cleaning, and membrane filtration performance affected by $\mathrm{pH}$ and temperature and so on. 
Transmembrane pressure of the ultrafiltration process in high influent turbidity increase rapidly, small organic molecules, especially trace organic pollutants removal effect is poor. So, the ultrafiltration technology should be used in combination with other process.

The ultrafiltration process commonly used with enhanced coagulation, activated carbon and biological pretreatment process. For the excellent quality source water, can directly enter the ultrafiltration membrane filtration, without chemical treatment. When the turbidity of raw water is high, should add coagulation sedimentation unit before the membrane unit, to expand the scope of application of ultrafiltration by turbidity. When the source water is high concentration of algae, can be arranged the floatation pool before the membrane unit for processing. When the raw water polluted by organic matter pollution, need to be added removal processing unit before membrane unit, such as the use of activated carbon adsorption. Or the small molecular organic flocculated into large particles and filter removal by subsequent membrane [14].

The ultrafiltration membrane water treatment technology has a wide application prospect in China, the current domestic and global processing techniques for ultrafiltration membrane water mostly been expanded in the promotion stage. The formation of a certain scale membrane production enterprises in China have Tianjin MOTIMO (mainly for sewage treatment), Hainan Litree (mainly for the water treatment).

\section{CONCLUSION}

Ultrafiltration technology used in water treatment as the new generation technology, draw more and more attention. The ultrafiltration membrane technology can be used in large scale depends largely on the membrane material itself, also depends on the membrane production conditions and process. This paper reviews the development and research trends of preparing ultrafiltration membrane material, and analyzes its application prospect in water treatment of drinking water.

\section{PROSPECT}

At present, global enterprises have been able to produce some of excellent performance ultrafiltration membrane, the specific membrane (such as PVDF) have also formed a certain scale of production in China. But for how to select the modified material in the modified ultrafiltration membrane preparation under the condition, and its modified ultrafiltration membrane can has a wide scope of application, which is mostly in the research stage. Due to the limitations of conventional water treatment process, with the increasing environmental pollution and the China and any other country's national drinking water standard improvement, therefore should under the original basis, further developed the excellent performance, strong adaptability, and high performance to price ratio membrane products, and actively promote to the municipal water treatment and drinking water treatment market to solve the future City water resources crisis, and improving the safety of drinking water.

\section{REFERENCES}

[1] L. L. Zhang and G. Ping, "Research progress of microfiltration and ultrafiltration technology for treatment of micro-polluted source water," membrane science and technology in China, vol. 34, pp. 5663, 2008.

[2] Y. X. Yang, W. B. Wu, and M. Zhang, "Research progress and development trend of preparing ultrafiltration membrane materials," grain and oil in China, vol. 68, pp. 17-25, 2005.

[3] W. Jiao and S. L. Ming, "Ultrafiltration membrane materials and the trend of development," chemical engineering and equipment in China, pp. 71-84, 2008.

[4] K. J. Kim, A. G. Fane, C. J. D Fell, and D. C. Joy, "Fouling mechanisms of membranes during protein ultrafiltration," J. Membr. Sci., vol. 68, no. 1-2, pp. 79-91, 1992.

[5] B. Georges, H. D. Robert, and L. Z.Andrew, 'The behavior of suspensions and macromolecular solutions in crossflow microfiltration," J. Membr. Sci., vol. 96, no. 1-2, pp. 1-58, 1994.

[6] G. Q. Wang and X. F. Wang, The polymer modified, China Light Industry Press, 2000.

[7] H. Cherdron, M. Haubs, F. Herold et al., "Miscible blends of polybenzimidazole and polyaramides," J. Appl. Polym. Sci., vol. 53, no. 5, pp. 507-509, 1994.

[8] O. Hirogoshi and K. Noboru, "Hydrophilic PS membrane and there preparation", JP. Patent 04-243531, Aug 31, 1992.

[9] X. L. Yin and H. Deng, "PVDF hollow fiber membrane," The morphology and structure of polymer materials science and engineering in China, vol. 14, no. 6, pp. 108-110, 1998.

[10] S. P. Nunes and K. V. Peninemann, "Ultrafiltration membranes from PVDF/PMMA blends," J Membr Sci, vol. 73, pp. 25-35, 1992.

[11] S. H. Yang and G. Q. Sun, "Study on flat ultrafiltration," water treatment technology in China, vol. 20, no. 6, pp. 365-369, 1994.

[12] B. G. Ulbricht, "Surface modification of ultrafiltration membrane by low temperature plasma," J. Membr. Sci, vol. 111, no. 2, pp. 193-215, 1996.

[13] X. F. Lu, S. Y. Chen, and C. Z. Li, "Surface active agent of modified ultrafiltration membrane," membrane science and technology, vol. 17, no. 4, pp. 6-41, 1997.

[14] G. B. Li, Y. L. Yang, and X. Li, "Some thoughts on conventional treatment of city drinking water technology upgrading," membrane technology forum in China, 2007.

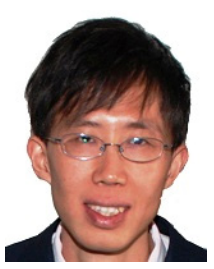

Aiyin Chen was born in Shanxi province of China, on september 18th, 1979. He graduated in environmental science from Nankai university located in Tianjin, and obtained the doctorate of science in 2008. He focused on the field of water pollution control.

He's working for Centre of Mohurd for New-tech in Water Treatment Industrialization as deputy chief engineer. He has published several papers on water pollution control, such as the paper entitled "Isolation and identification of Nitrobacteria adapted to low temperature" (Switzerland, Trans Tech Publications, 2012)and "Screening and Applocation of Nitrifying Bacteria at Low Temperature"(Singapore, IACSIT Press,2011).

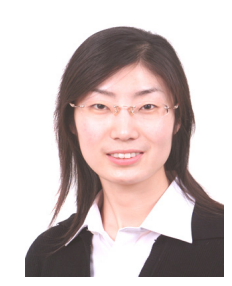

Qian Fan was born in Hebei province of China, on october 29th, 1982. She graduated in department of architecture and engineering from Beijing University of Technology located in Beijing, and obtained the master degree of engineering in 2008. She focused on the field of water pollution control.

She's working for Centre of Mohurd for New-tech in Water Treatment Industrialization as .researcher after graduating.

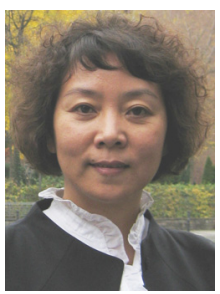

Qing Tian was born in Tianjin of China, on july 18th, 1964. She graduated in Chemical Machinery and Equipment department from East China University of Science and Technology located in Shanghai, and obtained the bachelor of engineering in 1987. She focused on the field of water pollution control.

She's working in Center of Mohurd for New-Tech in Water Treatment Industrialization as vice director. Since Jan 2007, and she had worked in National Urban Water Supply and Drainage Engineering Technology Research Center as office director. 